\title{
Calendula officinalis L. bitkisinin morfolojik özellikleri, ekstre içeren topikal ilaç formülasyonu geliştirilmesi ve in vitro değerlendirilmesi*
}

\author{
Morphological characteristics of Calendula officinalis L. plant, development and in vitro evaluation of \\ extract loaded topical drug formulation \\ Umay Merve Güveni, Selen Arslanii, Melike Betül Çıraciii, Serpil Demirci Kayıraniv \\ 'Dr.Öğr.Üyesi, Çukurova Üniversitesi Eczacılık Fakültesi, Farmasötik Teknoloji AD., https://orcid.org/0000-0003-1547-0817 \\ iYük.Lis.Öğr., Çukurova Üniversitesi Eczacılık Fakültesi, Farmasötik Teknoloji AD., https://orcid.org/0000-0003-4384-5460 \\ iiiYük.Lis.Öğr., Çukurova Üniversitesi Eczacılık Fakültesi, Farmasötik Botanik AD., https://orcid.org/0000-0001-8114-9592 \\ ivDoç.Dr. Çukurova Üniversitesi Eczacılık Fakültesi, Farmasötik Botanik AD., https://orcid.org/0000-0001-8340-3347
}

öz

\begin{abstract}
Amaç: Çalışmamızda Calendula officinalis'in morfolojik değerlendirmesi ve geleneksel kullanımları verilmiştir. Hazırlanan Calendula officinalis ekstresinin topikal uygulabilmesi için taşıyıcı olarak kullanılabilecek mikroemülsiyon geliştirmesi amaçlanmıştır.

Yöntem: Calendula officinalis'in bitki örnekleri botanik bahçesinden toplanmış ve herbaryuma yerleştirilmiştir. Üçgen faz diyagramları, yağ ve farklı oranlarda farklı yüzey aktif madde/yardımcı yüzey aktif maddenin kombinasyonları kullanılarak hazırlanıştır. Seçilen mikroemülsiyonların daha sonra damlacık boyutu, polidispersite indeksi, pH, zeta potansiyeli ve reoloji açısından karakterizasyonları yapılmıştır.

Bulgular: Faz diyagramlarından elde edilen Calendula officinalis ekstresi yüklü kararlı mikroemülsiyonlar başarılı şekilde formüle edilmiştir. Geliştirilen formülasyonlar, $208.24 \pm 2.28,232.66 \pm 4.46$ ve $254.82 \pm 6.84 \mathrm{~nm}$ damlacık boyutu, $0.22 \pm 0.04,0.27 \pm 0.03$ ve $0.26 \pm 0.03, \mathrm{pH} 5.40 \pm 0.10,5.62 \pm 0.12$ ve $5.58 \pm 0.08$ değerinde polidisperslik indeksi göstermiştir. Formülasyonlar şeffaf elde edilmiş ve nötr zeta potansiyel değeri göstermiştir. Mikroemülsiyonların bu çalışmada yüksek kararlılığa sahip oldukları görülmüştür.

Sonuç: Calendula officinalis ekstresi yüklü mikroemülsiyon sistemin, sedef hastalığının klinik araştırmalarında ve topikal tedavisinde kullanılabilmesi için umut vaat edici bir ilaç taşıyıcı olabileceği düşünülmektedir.
\end{abstract}

Anahtar Kelimeler: Calendula officinalis, Topikal formülasyon, Mikroemülsiyon, ỉlaç taşıyıcı sistem

\section{ABSTRACT}

Aim: This work aimed to develop microemulsion which can be used as vehicles for the topical application of Calendula officinalis extract. The morphological evaluation and traditional uses of $\mathrm{C}$. officinalis were given in this study.

Methods: The plant specimens of $\mathrm{C}$. officinalis were collected from the botanical garden and deposited in the herbarium. The pseudoternary phase diagrams were constructed based on oil and a combination of different surfactant/cosurfactant at different ratios. The selected microemulsions were then characterized for droplet size, polydispersity index, $\mathrm{pH}$, zeta potential and rheology.

Results: Calendula officinalis extract loaded stable microemulsions were successfully formulated based on the selected compositions from the phase diagrams. The developed formulations have shown a globule size of $208.24 \pm 2.28,232.66 \pm 4.46$ and $254.82 \pm 6.84 \mathrm{~nm}$, a polydispersity index of $0.22 \pm 0.04,0.27 \pm 0.03$, and $0.26 \pm 0.03, \mathrm{pH} 5.40 \pm 0.10,5.62 \pm 0.12$, and $5.58 \pm 0.08$. The formulations appeared transparent and the zeta potential result was neutral. The studied microemulsions showed good stability.

Conclusion: Calendula officinalis extract loaded microemulsion system may be a promising carrier for further development into a topical formulation and clinical trials in the treatment of psoriasis.

Keywords: Calendula officinalis, Topical formulation, Microemulsion, Drug delivery system

*Mersin Üniversitesi Tıp Fakültesi Lokman Hekim Tıp Tarihi ve Folklorik Tıp Dergisi, 2022; 12 (1): $105-115$

DOI: $10.31020 /$ mutftd.980661

e-ISSN: 1309-8004, ISSN 1309-761X

Geliş Tarihi - Received: 09 Ağustos 2021; Kabul Tarihi - Accepted: 08 Kasım 2021

iletişim - Correspondence Author: Umay Merve Güven <uguven@cu.edu.tr> 


\section{Giriş}

Calendula officinalis L. Asteraceae familyasına ait bir tür olup Türkiye'de "Aynısafa" adıyla tanınmaktadır. Türkiye'de Calendula cinsinin üç türü bulunmaktadır $C$. arvensis türünde, dilsi çiçekler fillarilerin uzunluğundan iki kat daha kısa; kapitula küçük ve daima tek yıllık bir türüdür. C. suffruticos türü çok yıllık, gövde tabanın üst kısmındaki bir bölümde odunlaşmış; yapraklar genellikle dişli-kıvrımlı; aken gagası belirgin uzamış, sıklıkla halka halinde yatık bir türdür. Son olarak $C$. officinalis türü ise gövde otsu veya sadece tabanda odunsu; bitki genellikle tek yıllık veya kısa yaşamda çok yıllık; yapraklar tam veya hafif parçalı, aken gagası güçlü içe kıvrık bir türüdür. C. officinalis türü ülkemizde doğal olarak yetişen bir tür değildir, bahçelerde süs olarak yetiştirilir. Dünyanın birçok yerinde kültüre alınmıştır ve genellikle geçici olarak kaydedilmiştir ve kökeni bilinmemektedir. ${ }^{1}$

C. officinalis'in bitkisel bir ilaç olarak ilk kullanımının, XII. yüzyılda Orta Çağ'da, sindirim problemlerini, adet ağrılarını ve çeşitli cilt lezyonlarını tedavi etmek için olduğu kaydedilmiştir. Özellikle yara iyileşmesindeki rolü nedeniyle XIII. yüzyılda İngiltere'ye ve başka bölgelere yayıldığı sonucuna ulaşılmıştır. Antiseptik ve antienflamatuar olarak balsamların ve kremlerin bileşiminde kullanılmıştır. İltihaplar ve deri yaraları için bir tedavi aracı olarak kullanımını açıklayan çok sayıda rapor vardır: çay halinde göz yıkama suyu olarak veya gargara halinde, konvülsiyonlar, oral ve boğaz mukozası iltihaplanmaları için, diüretik ve terletici olarak; cilt pişikleri ve diğer iltihaplı durumların tedavisinde kullanıldığı kaydedilmiştir. ${ }^{2}$

Türkiye'de yapılan etnobotanik çalışmalarda $C$. officinalis'in halk arasında sedef hastalı̆ı̆ının tedavisinde kullanıldığı kaydedilmiştir. C. officinalis çiçeklerinin krem şeklinde haricen egzema ve sedef hastalığında, toprak üstü kısımlarının merhem şeklinde haricen egzema ve sedef hastalığında ve yine toprak üstü kısımlarının dekoksiyon halinde dahilen sedef hastalığııın tedavisinde kullanıldığı belirtilmiştir. ${ }^{3-5}$

Sedef hastalığı, hiper proliferasyon ve epidermal keratinositlerin zayıf farklılaşması ile karakterize, kronik, bulaşıcı olmayan, immün aracılı bir cilt hastalığıdır. ${ }^{6}$ Hastalığın tedavisinin zor olması, hastada psikolojik rahatsızlıklara sebep olabilmekte ve hastanın günlük yaşamsal faaliyetlerini engelleyebilmektedir. Bu durum hastanın düşük kalitede yaşam sürmesine neden olmaktadır. Sedef hastalığında vakaların çoğunda, sistemik yan etkilerden kaçınmak amacıyla topikal kortikosteroidler önerilmektir. Kortikosteroidlerin düşük çözünürlük özellikleri ve büyük molekül yapıları gibi topikal uygulamaya elverişsiz fizikokimyasal özellikleri stratum korneum tabakasına yeterince nüfuz edememesine sebep olmaktadır. Bu durum, tedavideki etkinliklerini düşürmektedir. ${ }^{7-9}$

Lityum, $\beta$-blokerler ve antimalaryal ilaçların psöriazis lezyonlarının başlamasından ya da alevlenmesinden sorumlu olduğu bilinmektedir. ${ }^{10,11}$ Günümüzde sedef hastalığı gibi cilt hastalıklarında kombinasyon halinde veya tek başına farklı formlarda birçok bitki ekstraktının kullanımı ile ilgili çalışmalar mevcuttur. $C$. officinalis'in yapraklar kısımları polifenoller, alkaloidler, steroidler, tanenler ve flavonoidler bakımından zengindir. Çiçek kısımları hakkında birçok kullanım bildirilirken, geleneksel olarak yapraklar kısımları ise enflamasyon gelişmiş yaralarda, yanıklarda ve ülserlerde kullanılmaktadır. Ayrıca antienflamatuar ve yara iyi edici özelliklerinden dolayı egzema ve sedef hastalığında kullanımı yaygın olarak bilinmektedir. Bilimsel olarak yaprakların antimikrobiyal, hepatoprotektif ve yara iyileştirici aktiviteye sahip olduğu yapılan çalışmalarla gösterilmiştir. ${ }^{12}$

Deri, vücudumuzu çevreden gelebilecek etkilerden savunan ve bununla birlikte sıcaklık ve su kaybını da düzenleyen önemli bir organdır. Derinin büyük bir alan kaplaması ve uygulamada kolaylık sağlamasından dolayı topikal ilaç uygulama yolu, ilaçların sistemik veya lokal etki sağlaması amacıyla ilaç uygulamada sıklıkla tercih edilmektedir. Derinin koruyucu işlevi esas olarak tabakalı bir skuamöz epitel olan epidermise ait olan stratum korneumdan kaynaklanmaktadır. Stratum korneum, dış uyaranlarla doğrudan temas halinde olan 
epidermisin yüzeysel tabakasıdır., ${ }^{7,9}$ Derinin bu savunma mekanizmaları, kimyasal maddelerin deriden absorbsiyonuna engel olabiliyorken, geliştirlen formülasyonlarla birlikte ilaçların absorbsiyonu ve biyoyararlanımları arttırılabilmektedir. Krem, jel, pomad ve losyonlar gibi yarı katı ilaç formülasyonları, cilde uygulanma kolaylığı ve ilaç salımı sağlamalarıyla topikal tedavi için en çok tercih edilen farmasötik şekillerdir. Modern ilaç taşıyıcı sistemlerin geliştirilmesi ile topikal uygulamada da alternatif sistemler geliştirilmiştir. ${ }^{13}$

Mikroemülsiyonlar, makroskopik olarak tek fazlı, termodinamik açıdan kararlı, çok bileşenli sıvılar, optik berraklık ve yağ, su ve yüzey aktif maddenin izotropik karışımları ve sıklıkla tek tip küresel damlacıklardan oluşan bir yardımcı yüzey aktif madde ile kombinasyon halinde hazırlanan sistemlerdir. ${ }^{13,14}$ Bu sistemler günümüzde, geniş bir ilaç molekülü yelpazesini bir araya getirerek ilaç taşıyıcı sistem olarak kullanımı konusundaki önemli potansiyelleri nedeniyle farmasötik amaçla geliştirilmektedir. Topikal uygulanmanın yanı sıra oral, parenteral ve pulmoner uygulama için de biyoyararlanımı artıran ilaç taşıyıcı sistemleri olarak pek çok avantaj sunmaktadır. ${ }^{14}$

Mikroemülsiyonlar, geleneksel formülasyonlara kıyasla gelişmiş ilaç çözünürlüğü, iyi termodinamik stabilite, üretim kolaylığı ve transdermal uygulama üzerindeki artırıcı etkisi gibi çeşitli avantajlar sunmaktadır. ${ }^{13}$ Mikroemülsiyonlar, topikal olarak uygulanan etkin maddelerinin cilt bariyerlerini geçerek penetrasyonu artırma yeteneğine sahip olmakla birlikte, gelişmiş çözünme kapasiteleri sayesinde zayıf çözünür bir ilaç etkin madde için de uygun bir taşıyıcı sistem görevi görmektedir. ${ }^{15}$

Bu çalışmanın esas amacı, sedef hastalığında halk arasında kullanımı bulunan Calendula officinalis bitkisinin genel morfolojik özelliklerinin incelenmesi ve deskripsiyonun yazılması, bitkiden hazırlanan ekstre ile topikal amaçla kullanılabilecek alternatif bir mikroemülsiyon formülasyonu geliştirilmesi ve karakterizasyonunun araştırılmasıdır.

\section{Yöntem}

\section{Gereç}

Formülasyon çalışmamızda, yüzey etkin madde olarak Tween ${ }^{\circledR} 20$ (Sigma Aldrich, Almanya), yardımcı yüzey etkin madde olarak propilen glikol (Sigma Aldrich, Almanya), yağ fazı olarak izopropil miristat (Merck, Almanya) kullanılmıştır. Ekstraksiyon için saf su, geri çeviren soğutucu ve Rotary Evaporatör kullanılmıştır. Kullanılan tüm kimyasal maddeler analitik kalitede seçilmiştir.

\section{Bitki materyali}

Çalışmamızda, Çukurova Üniversitesi Ali Nihat Gökyiğit Tıbbi ve Aromatik Bitkiler Bahçesi'nde, arasında yer alan Calendula officinalis örnekleri ile çalışılmıştır. Calendula officinalis örnekleri Mart 2021 tarihinde Çukurova Üniversitesi Ali Nihat Gökyiğit Botanik Bahçesi'nden toplanarak Çukurova Üniversitesi Eczacılık Fakültesi Herbaryumu (CUEF)'na getirilmiştir. Herbaryumda preslenerek kurutulan örnekler herbaryum materyali haline getirilmiş ve üzerinde morfolojik incelemeler yapılmıştır. Morfolojik incelemeler stereo mikroskop (Olympus SZ51, Almanya) ile yapılmıştır. (CUEF1700, CUEF1701)

\section{Ekstraksiyon}

Calendula officinalis türüne ait yaprak ve çiçekli örnekler Mart 2021 tarihinde botanik bahçesinden toplanmıştır. Üzerindeki toz ve kirlerden arındırılan örnekler gölgede kurutulmaya bırakılmıştır. Waring blender ile toz hale getirilen örnekler $(250 \mathrm{~g})$, sekiz saat boyunca $45^{\circ} \mathrm{C}$ 'de çözücü olarak saf su kullanılarak doğrudan geri çevirici soğutucu ile ekstraksiyon işlemi yapılmıştır. Elde edilen sıvı ekstrakt Whatman No. 1 filtre kağıdı ile filtrelenmiş ve $45^{\circ} \mathrm{C}^{\prime}$ de Rotary evaporatör yardımı ile çözücüsü buharlaştırılmıştır. Geriye kalan saf ekstre cam şişelerde $-20^{\circ} \mathrm{C}$ de muhafaza edilmiştir. ${ }^{16}$ 


\section{Faz Diyagram}

Emülsiyon oluşum alanları üçlü faz diyagram çalışmaları ile belirlenmektedir. Çalışmamızda dış fazı su iç fazı yağ olacak şekilde hazırlanan mikroemülsiyonlar, bu diyagramlar ile açıklanmıştır. Mikroemülsiyon bölgesi, faz diyagramında açık ve şeffaf formülasyonların gözlemlendiği alan olarak belirlenmiştir. Yüzey etkin madde ve yardımcı yüzey etkin maddeler farklı oranlarda (2:1, 3:1, 4:1) karıştırılarak (Smix) ve toplam on gram olacak şekilde dokuz ayrı formülasyon üzerinden hazırlanmıştır. 1: 9, 2: 8, 3: 7, 4: 6, 5: 5, 6: 4, 7: 3, 8: 2 ve 9: 1 oranlarında yağ ve Smix içeren sistemler elde edilmiştir. Su fazı, şeffaflık kaybı gözlemlenene kadar titrasyon işlemi sırasında hafifçe karıştıılarak her numuneye damla damla ilave edilmiştir. Gerekli miktar distile su eklenmesinin ardından numuneler berrak görünüme kavuşmuştur. Bu oranlar kaydedilerek, faz diyagramları bilgisayar programı aracılı̆ııla oluşturulmuştur. Her oran için $(2: 1,3: 1,4: 1)$ mikroemülsiyon alanları belirlenmiş ve en büyük alana sahip grup seçilmiştir. Formülasyonlar hazırlanırken, farkı mekanik karıştırıcı farklı hızlarda denenmiş su alma kapasitesi ve berraklık açısından en iyi sonuçlar 600 rpm hızda elde edilmiştir. ${ }^{17,18}$

\section{Mikroemülsiyon formülasyonunun hazırlanması}

Formülasyon titrasyon yöntemi kullanılarak hazırlanmıştır. En büyük alana sahip diyagramın ağılık merkezindeki yüzde oranlarına göre plasebo ve bitki ekstresi içeren mikroemülsiyon formülasyonları hazırlanmıştır. Yağ, yüzey etkin madde ve yardımcı yüzey etkin madde tartııı mekanik karıştırıcıda $600 \mathrm{rpm}$ hızda karıştırılmış ve oda sıcaklığında $\left(25^{\circ} \mathrm{C}\right)$ damla damla distile su eklenerek titre edilmiştir. ${ }^{14}$

\section{Mikroemülsiyon formülasyonunun karakterizasyonu}

Taze hazırlanan formülasyonlar, renk, koku ve estetik değerdeki değişiklikler gibi görünümleri açısından fiziksel olarak gün ışığı altında değerlendirilmiştir. Hazırlanan formülasyonların fiziksel stabilitelerini belirlemek üzere üç farklı test uygulanmıştır. Illk olarak numunelere 3000 rpm'de 30 dakika boyunca santrifüj uygulanmıştır. Ardından $45^{\circ} \mathrm{C}^{\prime}$ den $4^{\circ} \mathrm{C}^{\prime}$ ye kadar ısıtma-soğutma döngüsüne tabii tutulmuştur. Son olarak da donma ve tekrar çözülme döngüsü ile $-18^{\circ} \mathrm{C}^{\prime}$ ye getirilen numuneler tekrar $25^{\circ} \mathrm{C}$ 'de çözündürülmüştür. Bu testler üç tekrar olacak şekilde çalışılmış ve test sonucunda numunelerin fiziksel durumları incelenmiştir. Seyreltme işlemini taklit etmek amacıyla hazırlanan mikroemülsiyon formülasyonu sulu ortam ile 1:1, 1:9 ve 1:99 oranlarında seyreltilmiştir. Seyreltme, $25^{\circ} \mathrm{C}^{\prime}$ de beş dakika süre boyunca kuvvetli vorteksleme ile gerçekleştirilmiştir. ${ }^{19,20}$

Mikroemülsiyonların topikal uygulama için uygunluğunu belirlemek için $\mathrm{pH}$, damlacık boyutu, polidispersite indeksi (PDI) ve zeta potansiyeli ve reoloji gibi mikroemülsiyonların karakteristik özellikleri değerlendirilmiştir. Mikroemülsiyonların pH değerleri, bir dijital pH metre (WTW Profi Lab. pH 597, Almanya) ile ölçülmüştür. Tüm ölçümler üç tekrar halinde belirlenmiş ve ölçümlerin ortalamaları kaydedilmiştir. Formülasyonların damlacık boyutu ve PDI ölçümleri için Dinamik Işık Saçılım yöntemi (Nano ZS, Malvern Instruments, U.K.) kullanılmıştır. Damlacık boyutu ve PDI değerleri $25^{\circ} \mathrm{C}$ de altı ölçüm yapılarak tekrarlanmış ve ortalaması alınmıştır. Numunelerin zeta potansiyelini ölçmek için tek kullanımlık zeta hücreleri (Malvern Zetasizer Nano ZS) kullanıldı. Zeta potansiyeli, $40 \mathrm{~V} / \mathrm{cm}$ 'lik bir elektrik alanı altında Helmholtz-Smoluchowski denklemi kullanılarak elektroforetik hareketlilikten hesaplanmıştır. İşlem için yazılım içeren cihaz kullanılmış ve hesaplamalar yazılım ile yapılmıştır. Analizler, $25^{\circ} \mathrm{C}$ de altı ölçüm yapılarak tekrarlanmış ve ortalaması alınmıştır. Formülasyonların reolojik davranışları incelenmiştir. Analizler için Brookfield koni-plak reometre kullanılmıştır. Koninin açısı $1.565^{\circ}$ ve çapı $1.2 \mathrm{~cm}$ 'dir. Ölçümler $25^{\circ} \mathrm{C}^{\prime}$ de yapılımıştır. ${ }^{9,21,22}$ 


\section{Bulgular}

\section{Calendula officinalis'in Genel Botanik Özellikleri ve Deskripsiyonu}

Çukurova Üniversitesi Ali Nihat Gökyiğit Botanik Bahçesi'nde, Tıbbi ve Aromatik Bitkiler arasında yer alan Calendula officinalis örnekleri ile çalışılııştır (Şekil 1). Tüm bitki $25-30 \mathrm{~cm}$ boylarında, aromatik, otsu, çok dallı ve dik gövdelidir. Gövde; köşeli, tüylü ve tabandan yukarı doğru dallıdır. Kökler, yaklaşık $10 \mathrm{~cm}$ saçak kök şeklindedir. Yapraklar, alternan, gövdeyi sarıcı, 3,5x8 cm dikdörtgen mızraksı, dalgalı-dişli ve tüylüdür. Kapitulum, heterogam, radiyat, kalın, $5 \mathrm{~cm}$ çapında, tabanda iki sıra dizilmiş tüylü braktelerden oluşur. Çiçekler, her bir sapın ucunda bulunan kompozit çiçek başından oluşur. Çiçek başı, dışta $3-5 \mathrm{~cm}$ uzunluğunda iki tarafı da glandüler kıllarla kaplanmış, yoğun turuncu veya sarı renkli dilsi çiçeklerden ve iç kısımlarında turuncu renkli tüpsü çiçeklerden oluşur. Dilsi çiçekler, kenarları düzgün şekilli ve uç kısımları dişlidir. Dişi çiçekler üç dişli, erkek çiçekler iki dişlidir. Türde her ikisi de bulunduğu için bitki hermafrodittir. Meyve, yaklaşık 0.5-1 cm, dikenli, kuvvetli kavisli bir akendir (Şekil 2).

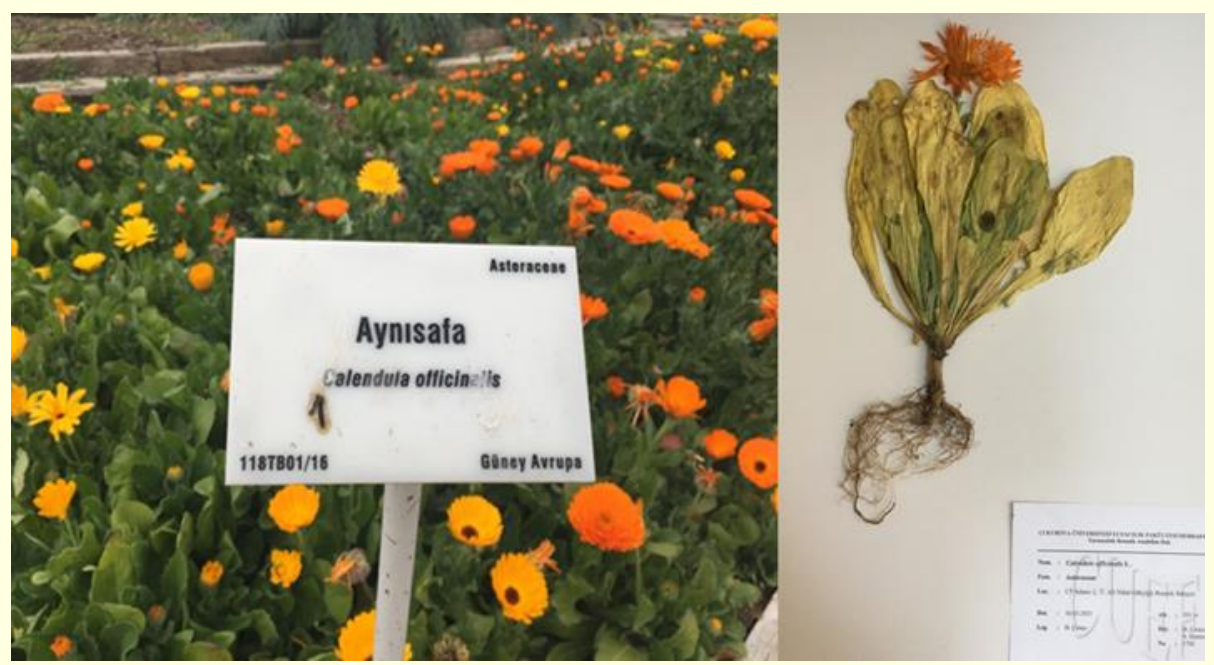

Şekil 1. Calendula officinalis L. Çukurova Üniversitesi Ali Nihat Gökyiğit Botanik Bahçesi ve Herbaryum Örneği Genel görünümü

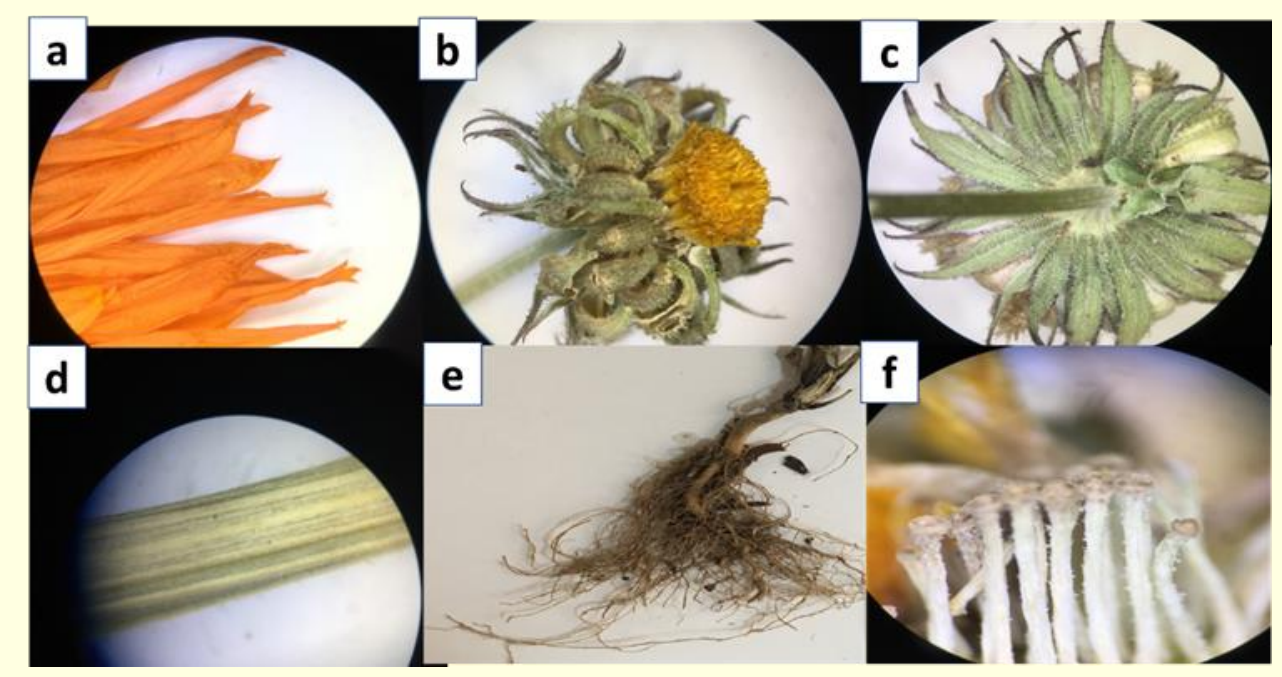

Şekil 2. Calendula officinalis L. Bitkisinin kısımları (a: Glandüler kıllarla kaplanmış dilsi çiçekler b: kapitulum ve tüpsü çiçekler c: tüylerle kaplı brakteler d:tüylü gövde e: saçak kök f: pistiller) 


\section{Mikroemülsiyon formülasyonu}

Tüm formülasyon bileşenleri ilaç formülasyonlarında dermal kullanıma uygun olarak belirlenmiştir. İdeal mikroemülsiyonları hazırlamak için öncelikle, mikroemülsiyonda yer alan bileşenlerin optimum konsantrasyon aralığı belirlenmektedir. Üçgen faz diyagramlarının oluşturulması, bileşenlerin gerekli konsantrasyon aralığını bulmayı kolaylaştırmaktadır. Çalışmamızda, üç farklı mikroemülsiyon oranı için üçgen faz diyagramları oluşturulmuştur (Şekil 3).
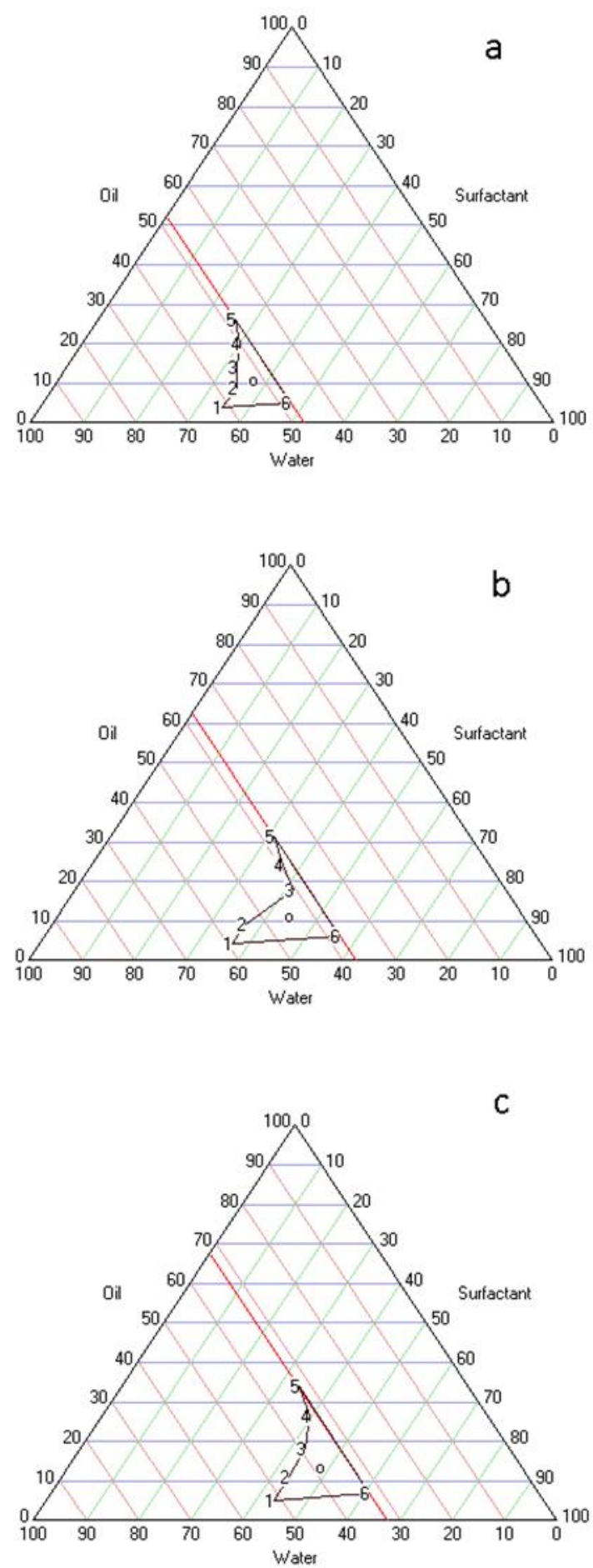

Şekil 3. Mikroemülsiyon formülasyonlarına ait üçgen faz diyagramları (a: 2:1, b:3:1, c:4:1) 
Oluşturulan üçgenlerin ağırlık merkezleri ile bileşenlerin uygun konsantrasyon aralıkları elde edilmiştir. Formülasyon içerikleri yüzde ağırlık cinsinden Tablo 1'de sunulmuştur. ME2:1, ME3:1, ME4:1 mikroemülsiyonların alanları sırasıyla 95, 157 ve 167 olarak belirlenmiştir. ME4:1 mikroemülsiyonu diğer mikroemülsiyonlara göre daha yüksek alana sahip olduğu görülmüştür. Formülasyonlara \%5 oranda ekstre eklendiğinde istenmeyen bir görünüm ve bulanıklık gerçekleşmemiştir.

Tablo 1. Mikroemülsiyon Formülasyon Bileşenleri

\begin{tabular}{llll}
\hline Bileşenlerin \% (A/A) Değerleri & ME2:1 & ME3:1 & ME4:1 \\
\hline IPM & 11.03 & 11.49 & 13.50 \\
Tween 20 & 24.75 & 32.97 & 38.40 \\
Propilen glikol & 12.37 & 10.99 & 9.60 \\
Distile su & 51.85 & 44.55 & 38.50 \\
\hline
\end{tabular}

\section{Mikroemülsiyon formülasyonunun karakterizasyonu}

Formülasyonların hazırlanmalarının ardından fiziksel özellikleri organoleptik olarak değerlendirilmiştir. Uzun süreli stabilitenin değerlendirilmesi için hızlandırılmış test yöntemleri gerekmektedir. Hazırlanan mikroemülsiyonlar merkez kaç kuvvetinin etkisiyle santrifüj gibi zorlu koşula maruz bırakılmış ve test sonrasında tek fazlı berrak görünümünü koruduğu ve kremleşme belirtisinin oluşmadığı gözlenmiştir. Isıma soğutma döngüsü ve dondurma çözündürme işlemleri sonrasında da formülasyonların ilk hazırlandıkları zamandaki görünümünü korudukları kaydedilmiştir. Seyreltme işlemi ile formülasyonların bozulmadan optik özelliklerini koruyarak suyla kolayca karışabildiği gözlenmiştir.

Formülasyonların fizikokimyasal özelliklerinin belirlenmesi için damlacık boyutu, PDI, zeta potansiyeli ve pH ölçümleri yapılmıştır. Ölçüm sonuçları Tablo 2' de ortalama değerleri ve standart sapmaları ile sunulmuştur. Formülasyonların damlacık boyutu $208.24 \pm 2.28$ ile $254.82 \pm 6.84 \mathrm{~nm}$ arasında bulunmuştur. Damlacık boyutlarının homojenliğini ifade eden PDI değerleri ise sırasıyla $0.22 \pm 0.04,0.27 \pm 0.03$ ve $0.26 \pm 0.03$ bulunmuştur. Tüm formülasyonların PDI değerleri, 0.3'ten küçüktür ve bu durum formülasyonların istenilen homojenliğe ulaştığını göstermektedir. ${ }^{22}$ Zeta potansiyel ölçümleri Tablo 2 'de belirtildiği gibi sırasıyla $0.244 \pm 0.058,0.216 \pm 0.072$ ve $0108 . \pm 0.042 \mathrm{mV}$ olarak ölçülmüştür.

Tablo 2. Mikroemülsiyon Formülasyonlarına ait karakterizasyonlar

\begin{tabular}{lllll}
\hline Formülasyon & $\mathbf{p H}$ & $\begin{array}{l}\text { Damlacık boyutu } \\
(\mathbf{n m})\end{array}$ & PDI & $\begin{array}{l}\text { Zeta potansiyeli } \\
(\mathbf{m V})\end{array}$ \\
\hline ME2:1 & $5.40 \pm 0.10$ & $208.24 \pm 2.28$ & $0.22 \pm 0.04$ & $0.244 \pm 0.058$ \\
ME3:1 & $5.62 \pm 0.12$ & $232.66 \pm 4.46$ & $0.27 \pm 0.03$ & $0.216 \pm 0.072$ \\
ME4:1 & $5.58 \pm 0.08$ & $254.82 \pm 6.84$ & $0.26 \pm 0.03$ & $0108 . \pm 0.042$ \\
\hline
\end{tabular}

Reoloji, mikroemülsiyonların karakterizasyonunu belirleme açısından önemli olan bir diğer parametredir. Şekil 4'te formülasyonların kayma gerilimine (shear stress) karşı kayma hızını (shear rate) gösteren reogramları sunulmuştur.
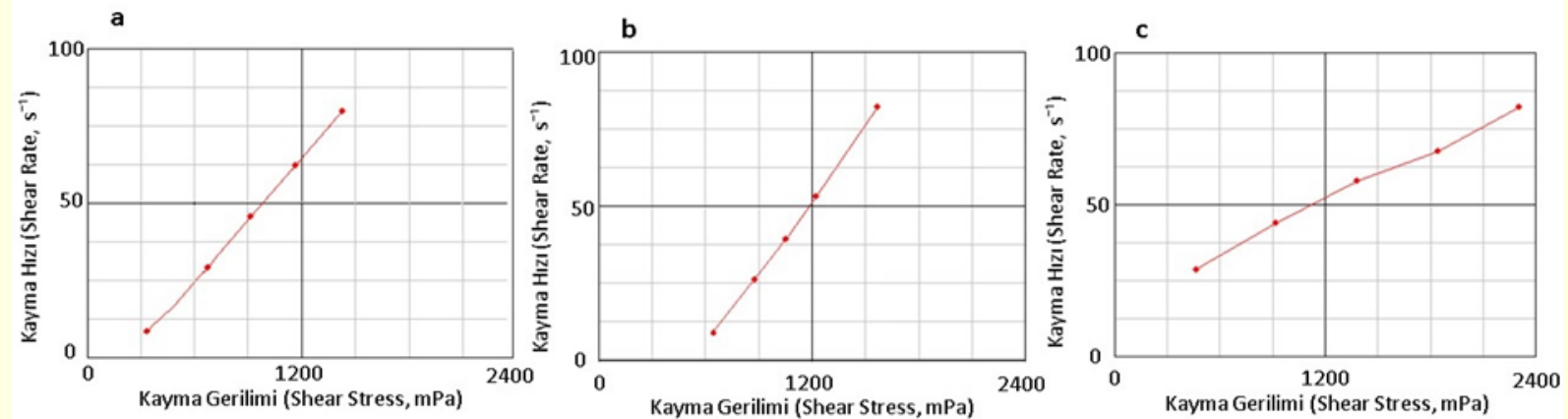

Şekil 4. Mikroemülsiyon formülasyonlarının kayma hızına karşı kayma gerilimlerine ait reogramları (a: ME2:1, b:ME3:1, c:ME4:1) 


\section{Tartışma}

Günümüzde tıbbi bitkilerin halk arasında kullanımlarını değerlendirmek ve bu bilgileri bilimsel araştırmalarla desteklemek, tedavi amacıyla kullanımlarını sağlama açısından çok önemlidir. Tüm dünyada olduğu gibi ülkemizde de pek çok tıbbi bitki çeşitli hastalıkların tedavisinde yaygın olarak kullanılmaktadır. Bu kullanımlarını, bilimsel veriler ışığında uygun koşullarda elde edilen bitkilerin ekstraksiyonu ve uygun bir taşıyıcı sistem içerisinde hastaya sunulması konuları etkinlik ve güvenlik açısından son derece önemlidir.

Bu çalışmada, Calendula officinalis bitkisinin genel botanik özellikleri ve deskripsiyonu araştırılmıştır. Bitkinin toprak üstü kısımları ile hazırlanan ekstre kullanılarak, sedef hastalığında kullanılmak üzere topikal mikroemülsiyon formülasyonu geliştirilmiş ve in vitro karakterizasyon çalışmaları yapılmıştır.

Calendula officinalis tek yıllık veya çok yıllık otsu bir bitkidir. Bitkinin; çiçek, yaprak ve köklerinde; terpinoidler, flavonoidler, kumarinler, kinonlar, uçucu yağlar taşıdığı, Dünya'da ve Türkiye'de birçok hastalıkta dahilen ve haricen kullanılan bir tür olduğu yapılan çalışmalarla ortaya konmuştur. Çalışmalar, bunun çeşitli ayurvedik ve homeopatik tıp sistemlerinde önemli bir bileşen olduğunu, deneysel hayvan modellerinde ve klinik deneylerde bilimsel taramalar yoluyla etkinliğini doğrulamak için hala çaba gösterilmesi gerektiğini öne sürmüştür. ${ }^{24,25}$

Türkiye'de cilt hastalıklarında geleneksel olarak kullanılan bitkiler üzerine yapılmış bir çalışmada, $C$. officinalis çiçeklerinin krem şeklinde haricen egzema ve sedef hastalığı için, toprak üstü kısımlarının merhem şeklinde haricen egzema ve sedef hastalığı için ve yine toprak üstü kısımlarının dekoksiyon halinde dahilen sedef hastalığı için kullanıldığını kaydedilmiştir. C. officinalis çiçekleri yüksek flavonoid içeriği nedeniyle güçlü antioksidan etkiye sahiptir. ${ }^{5}$

Mikroemülsiyonlar termodinamik açıdan kararlı olması, üretimlerinin kolay ve büyük ölçekte yapılabilmesinin mümkün olması ilaç endüstrisi için avantaj olarak karşımıza çıkmaktadır. Bu sistemlerin en önemli üstünlüklerinden birisi, lipit bazlı sistemler olması sebebi ile cilde daha derin penetrasyon sağlamalarıdır., ${ }^{9,26}$

Yağın, yüzey etkin maddenin, yardımcı yüzey etkin maddenin seçilerek faz diyagramları oluşturulması, herhangi bir ilacın mikroemülsiyon bazlı formülasyonlarının geliştirilmesi için ön koşullardır. Mikroemülsiyon sistemler bileşenlerinde yüksek oranda yüzey etkin madde ve yardımcı yüzey etkin madde içermeleri sebebi ile dermal kullanımda cilt üzerinde iritasyona sebep olabilmektedir. Bu durumu elimine etmek için sistem bileşenlerinin optimum miktarlarını tayin ederken üçgen faz diyagramları geliştirilmektedir. Mikroemülsiyon bölgesinin tayin edilmesi ve bölgenin ağırlık merkezinin belirlenmesi, formülasyonun tahriş olasılığını ortadan kaldırmak için önemli bir yöntem olarak kullanılmaktadır. ${ }^{21,27}$ Faz diyagramlarının ağırlık merkezi, plasebo mikroemülsiyon formülasyonlarını hazırlamak için bileşenlerin yüzdesini sağlamıştır. Tüm formülasyonların net ve şeffaf oluştuğu gözlenmiştir. Farklı yüzey etkin madde/yardımcı yüzey etkin madde oranları kullanılarak üçgen faz diyagramları başarıyla oluşturulmuş ve mikroemülsiyon bölgeleri tanımlanmıştır.

Mikroemülsiyonun bileşimine giren maddeler, mikroemülsiyonun kullanılış yoluna uygun seçilmelidir. Topikal kullanılacak bir mikroemülsiyon formülasyonunda kullanılan maddeler toksik olmamalı, irritan etki ve duyarlılık oluşturmayacak özelliğe sahip olmalıdır. ${ }^{28}$ Bu çalışmada mikroemülsiyonları hazırlamak için yağ fazı olarak IPM seçilmiştir. IPM, güçlü bir nüfuz artırıcı etkiye sahiptir ve ciltte difüzyon katsayısını artırabilmektedir. Önceki çalışmalar, IPM'nin yağ olarak topikal ilaçların yanı sıra kozmetik uygulamalarda da yaygın olarak kullanıldığını bildirmiştir. ${ }^{9}$ ideal formülasyon özelliklerine sahip mikroemülsiyonları hazırlamak için iyonik olanlara göre daha az toksik olduğu bilinen FDA onaylı noniyonik yüzey aktif madde olarak Tween ${ }^{\circ}$ 20 kullanılmıştır. Propilen glikol cilt ile uyumlu yapıda bir madde olması ile topikal ilaç formülasyonlarında tercih edilmektedir. Cilt ile uyumunun yanı sıra yüzey etkin madde konsantrasyonunu azaltmak ve yağ ile su fazı arasındaki yüzey gerilimini düşürmesi sebebi ile de kullanılmaktadır. ${ }^{17}$ 
Hazılanan formülasyonların stres testleri ile termodinamik olarak kararlı oldukları görülmüştür. Mikroemülsiyonda santrifüj, dondurma-çözündürme ve ısıtma-soğutma döngüsüne maruziyet sonrasında herhangi bir faz ayrışmasının olmadığı gözlenmiştir. Bu durum, mikroemülsiyonun formülasyonunda kullanılan bileşenlerin konsantrasyonlarının homojen ve stabil bir formülasyon vermek için uygun olduğu anlamına gelmektedir. Aynı zamanda, formülasyonun raf ömrü boyunca kararlılığını koruyacağı düşünülmektedir. ${ }^{20,21}$

Mikroemülsiyonların damlacık büyüklükleri görünür dalga boyundan daha küçük olması sebebi ile mikroemülsiyonlar partiküller ışığı geçirmekte ve saydam görünmektir. Ayrıca titrasyon yöntemiyle üretilen y/s tipi mikroemülsiyonların, genel olarak şeffaf ve homojen bir görüntüye sahip oldukları bilinmektedir. ${ }^{18,29}$ Topikal ilaçlarda hasta uyuncunun sağlanması ve tahriş edici hisleri önlemek amacıyla hazırlanan formülasyonların $\mathrm{pH}$ değerleri dikkate alınmaktadır. İdeal bir formülasyonda $\mathrm{pH}$ değeri, cilt $\mathrm{pH}$ 'sı ile uyumlu olarak dört ile yedi aralığında bir değerde olmalıdır. Hazırlanan formülasyonların ölçümler sonucunda ciltte rahatsızlık hissini en aza indirecek şekilde cilt $\mathrm{pH}^{\prime}$ sı ile uyumlu olduğu tespit edilmiştir. ${ }^{8,30}$ Formülasyonların farklı damlacık boyutları, farklı optimize edilmiş yağ ve kullanılan yüzey aktif madde fazları şeklinde yorumlanmıştır. Formülasyonların damlacık boyutlarının küçük olması, stratum korneumdan ilaç penetrasyonunun kolaylaşacağı anlamına gelmektedir. Penetrasyonun artması ile biyoyararlanımın artması hedeflenmiştir. ${ }^{30} \mathrm{PDI}$ değerinin küçük olması, geliştirilen mikroemülsiyonlardaki damlacıkların boyut dağılımının homojenliğini göstermektedir. Geliştirilen tüm formülasyonların 0.5 'in altındaki PDI değerine sahip olması, damlacıkların tekdüzeliğinin göstermekte ve damlacıkların boyutlarının yakın aralıkta olduğuna işaret etmektedir. ${ }^{9,23}$ Mikroemülsiyonların zeta potansiyel değerleri, noniyonik yüzey aktif maddeler içermesi sebebi ile nötr bir değere yakın bulunmuştur. Bu veri, yağ globülü yüzeyinde iyonik olmayan yüzey etkin maddenin herhangi bir önemli yük ( $> \pm 30 \mathrm{mV}$ ) oluşturmadığını göstermiştir. ${ }^{8,31}$ Mikroemülsiyon sistemlerin reolojik davranışı genellikle Newton akış modeline uygun olduğu bilinmektedir. Mikroemülsiyon sistemler iç fazlarının küçük damlacık boyutuna sahip olmaları sebebi ile tek fazlı bir sistem gibi davranıp, kayma hızına ve gerilime bağlı olmaksızın doğrusal bir akış özelliği göstermektedir. ${ }^{22,32}$ Karakterizasyon çalışmalarının sonuçlarına göre, optimum özelliklere sahip, topikal kullanıma uygun mikroemülsiyon formülasyonlarının geliştirildiği gözlenmiştir.

Doğrudan bitkisel ekstrelerin kullanımına oranla, mikroemülsiyon formülasyonlarında daha düşük ekstre içeriği seviyesi ile, daha yüksek membran geçirgenliği sunması sebebi ile daha iyi etkinlik sağlayabileceği öngörülmektedir. Bu durum, maliyeti düşürmekte ve ürünün yan etkilerini azaltmayı sağlayabilmektedir. ${ }^{17}$ Hastalık bölgesinde ilaç konsantrasyonunu iyileştirmek, oral yol ile kullanımda oluşabilecek sistemik toksisiteyi ve yan etkileri azaltmak için topikal uygulama ile bitkisel içerikli ilaç formülasyonu uygulamak, diğer ilaç uygulama yollarına göre avantajlı olabilmektedir. Sonuç olarak, hazırlanan mikroemulsiyon formülasyonunun deriye topikal yol ile ilaç uygulanması için uygun bir alternatif olabileceği düşünülmektedir.

\section{Bilgi}

Çalışmada herhangi bir mali destek bulunmamaktadır. Yapılan bu çalışma için herhangi bir çıkar çatışması ve anlaşmazlık bulunmamaktadır.

\section{Araştırmacı Katkı Oranı Beyanı}

Umay Merve Güven: Fikir, tasarım, danışmanlık/denetleme, analiz ve yorum, makale yazımı, eleştirel inceleme, kaynak ve fon sağlama, malzeme sorumluluğu.

Selen Arslan: Danışmanlık/denetleme, veri toplama ve işleme, analiz ve yorum, kaynak taraması, makale yazımı, malzeme sorumluluğu. 
Melike Betül Çıracı: Danışmanlık/denetleme, veri toplama ve işleme, analiz ve yorum, kaynak taraması, makale yazımı, malzeme sorumluluğu.

Serpil Demirci Kayıran: Fikir, tasarım, danışmanlık/denetleme, analiz ve yorum, makale yazımı, eleştirel inceleme, kaynak ve fon sağlama, malzeme sorumluluğu.

\section{Kaynaklar}

1. Peter HD. Flora of Turkey and Aegean Islands. Vol 5. Edinburgh, Edinburgh University Press 1985.

2. Jarić S, et al. Traditional wound-healing plants used in the Balkan region (Southeast Europe). J Ethnopharmacol 2018;211:311-28.

3. Deniz L, Serteser A, Kargıoğlu M. Uşak Üniversitesi ve Yakın çevresindeki bazı bitkilerin mahalli adları ve etnobotanik özellikleri. AKU-FEMÜBiD 2010;10(1):57-72.

4. Uğulu I. Fidelity level and knowledge of medicinal plants used to make therapeutic Turkish baths. Stud Ethno-med 2012;6(1):1-9.

5. Erarslan ZB, Ecevit-Genç G, Kültür Ş. Medicinal plants traditionally used to treat skin diseases in Turkey-eczema, psoriasis, vitiligo. Ankara Ecz Fak Dergisi 2020;44(1):137-66.

6. Greaves MW, Weinstein GD. Treatment of psoriasis. N Engl J Med 1995;332(9):581-89.

7. Naldi L. Epidemiology of psoriasis. Curr Drug Targets Inflamm Allergy 2004;3(2): 121-28.

8. Pandey SS, et al. Cyclosporine laden tailored microemulsion-gel depot for effective treatment of psoriasis: In vitro and in vivo studies. Colloids Surf B Biointerfaces 2020;186:1-8.

9. Ryu KA, et al. Topical delivery of coenzyme q10-loaded microemulsion for skin regeneration. Pharmaceutics 2020;12(4):1-15.

10. Abel EA, et al. Drugs in exacerbation of psoriasis. J Am Acad Dermatol 1986; 15(5):1007-22.

11. Kim GK, James QR. Drug-provoked psoriasis: is it drug induced or drug aggravated?: understanding pathophysiology and clinical relevance. J Clin Aesthet Dermatol 2010; 3(1): 32-38.

12. Rigane $G$, et al. Investigation into the biological activities and chemical composition of Calendula officinalis L. growing in Tunisia. Int Food Res J 2013; 20(6):3001.

13. Shah RR, et al. Preparation and evaluation of aceclofenac topical microemulsion. Iran J Pharm Res 2010;9(1):5-11.

14. Üstündağ Okur N, Çağlar EŞ, Siafaka PI. Novel ocular drug delivery systems: An update on microemulsions. J Ocul Pharmacol Ther 2020;36(6):342-54.

15. Grampurohit N, Ravikumar P, Mallya R. Microemulsions for topical use-a review. Ind J Pharm Edu Res 2011;45(1):100-07.

16. Das K, Deb S, Karanth T. Phytochemical screening, metallic ion content and from its impact on Anti psoriasis activity of Calendula officinalis and Phlebodium decumanum aqueous leaf extracts in animal experiment model. Galenos 2019;16(3):292-302.

17. Das $S$, et al. Development of microemulsion based topical ivermectin formulations: Pre-formulation and formulation studies. Colloids Surf. B: Biointerfaces 2020;189:1-8.

18. Öztürk AA, Güven UM. Cefaclor monohydrate loaded microemulsion formulation for topical application: Characterization with new developed UPLC method and stability study. J Pharm Res. 2019;23(3):426-40.

19. Momoh MA, et al. Microemulsion-based approach for oral delivery of insulin: formulation design and characterization. Heliyon 2020;6(3):1-8.

20. Abdulbaqi MR, Rajab NA. Preparation, Characterization and Ex vivo Permeability Study of Transdermal Apixaban O/W Nanoemulsion Based Gel. Iraqi J Pharm Sci 2020;29(2):214-22.

21. Zhang J, Froelich A, Michniak-Kohn B. Topical delivery of meloxicam using liposome and microemulsion formulation approaches. Pharmaceutics 2020;12(3):1-24.

22. Çilek A, Çelebi N, Tirnaksiz F. Lecithin-based microemulsion of a peptide for oral administration: preparation, characterization, and physical stability of the formulation. Drug Deliv 2006;13(1):19-24.

23. Hung WH, et al. Preparation and Evaluation of Azelaic Acid Topical Microemulsion Formulation: In Vitro and In Vivo Study. Pharmaceutics 2021;13(3):1-8.

24. Arora D, Rani A, Sharma AA. Review on phytochemistry and ethnopharmacological aspects of genus Calendula. Pharmacogn Rev 2013;7(14):179-87.

25. Verma PK, et al. Phytochemical ingredients and Pharmacological potential of Calendula officinalis Linn. Int J Pharm Biomed Res 2018;4(2):1-17.

26. Jain A, Pooladanda V, Bulbake U. Liposphere mediated topical delivery of thymoquinone in the treatment of psoriasis. Nanomedicine NBM 2017;13(7):2251-62.

27. Kajbafvala A, Salabat A. Microemulsion and microemulsion gel formulation for transdermal delivery of rutin: Optimization, invitro/ex-vivo evaluation and SPF determination. J Dispers Sci Technol 2021;1-16.

28. Çelik A, Türkyılmaz A, Çelebi N. Mikroemülsiyonlar: Genel Özellikleri ve Farmasötik Amaçla Kullanımları. FABAD J Pharm Sci 2002;27:27-41.

29. Banh HL, Cave A. Determination of efficacy and toxicity of diclofenac microemulsion formulation for musculoskeletal pain: an observational study. BMC Res Notes 2020;13(1):1-4. 
30. Okur ME, Ayla Ş, Yozgatlı V. Evaluation of burn wound healing activity of novel fusidic acid loaded microemulsion based gel in male Wistar albino rats. Saudi Pharm J 2020;28(3):338-48.

31. Agrawal V, et al. Design and evaluation of microemulsion-based efinaconazole formulations for targeted treatment of onychomycosis through transungual route: Ex vivo and nail clipping studies. Colloids Surf. B: Biointerfaces 2021; 201:1-9.

32. Formariz TP, et al. Doxorubicin biocompatible $\mathrm{O} / \mathrm{W}$ microemulsion stabilized by mixed surfactant containing soya phosphatidylcholine. Colloids Surf B Biointerfaces 2006;51(1):54-61. 